\title{
Comorbidities of Chronic Obstructive Pulmonary Disease Patients at Respirology and Critical Care Outpatient Clinic Dr. Hasan Sadikin General Hospital, Bandung, Indonesia
}

\author{
Adrian Sebastian Suhendro, ${ }^{1}$ Prayudi Santoso, ${ }^{2}$ Silvita Fitri Riswari, ${ }^{3}$ Primal Sudjana ${ }^{2}$ \\ ${ }^{1}$ Faculty of Medicine Universitas Padjadjaran, ${ }^{2}$ Department of Internal Medicine Faculty of \\ Medicine Universitas Padjadjaran/Dr. Hasan Sadikin General Hospital Bandung, \\ ${ }^{3}$ Department of Microbiology and Parasitology Faculty of Medicine Universitas Padjadjaran
}

\begin{abstract}
Background: Chronic obstructive pulmonary disease (COPD) is a chronic disease that becomes one of the leading causes of death in the world. The COPD is usually accompanied by comorbidities that impact prognosis and increase patients' expenses. However, the comorbidities of COPD patients have not yet to be known in Dr. Hasan Sadikin General Hospital, Bandung, Indonesia. This study was aimed to determine the frequency, type and number of comorbidities accompanying COPD.

Methods: This study was a retrospective, cross-sectional study at the respirology and critical care outpatient clinic of Dr. Hasan Sadikin General Hospital, Bandung, Indonesia in 2012. Data were obtained from medical records of patients diagnosed with COPD and had an obstructive pulmonary function test result. Sampling technique in this study was total sampling. Data were classified by age, gender, smoking history and severity of disease and were analyzed to determine the frequency, type and number of comorbidities accompanying COPD.

Results: Thirty eight COPD patients with obstructive pulmonary function test results were analyzed. It consists of 31 males and 7 females with age ranged between 43-82 years and median age of 64 years. Severe obstruction was found in 15 of 38 patients. Comorbidities were found in 26 patients, and 2 patients had up to four comorbidities. The most common comorbidity was hypertension (9 of 38).

Conclusions: The majority of COPD patients had comorbidities and the most frequent comorbidity was hypertension. [AMJ. 2017;4(1):30-5]
\end{abstract}

Keywords: Chronic disease, chronic obstructive pulmonary disease (COPD), comorbidities

\section{Introduction}

Chronic obstructive pulmonary disease (COPD) is a chronic disease that is characterized by persistent airway limitation due to chronic inflammatory response in airway and lungs caused by hazardous particle or gas. ${ }^{1}$ Diagnosis of COPD is usually made on the basis of medical history taking, physical examination, and results from pulmonary function test. ${ }^{2}$

Worldwide, the prevalence of COPD is $4-10 \%$ of all population., ${ }^{3,4}$ The World Health Organization (WHO) has ranked COPD as the fourth leading cause of death. ${ }^{5}$ The prevalence of COPD in Asia Pacific is estimated about 6.3\% of all population. ${ }^{6}$
The COPD is mostly accompanied by comorbidities that can impact patients' prognosis, change the effectiveness of COPD therapy, cause potentially dangerous therapeutic interactions and increase patients' expenses in treating the disease..$^{2,7-9}$ The definition of comorbidity is the presence of one or more diseases or health conditions in an individual at a given time. ${ }^{10}$ Comorbidity is different from complication. Comorbidity can occur regardless of COPD, having the same cause $(\mathrm{s})$, or sharing the same risk factors. ${ }^{7,8}$ It has been shown that $96.4 \%$ COPD patients had one or more comorbidities. ${ }^{9}$ Cardiovascular disease, skeletal muscle dysfunction, metabolic syndrome, osteoporosis, depression and lung cancer are the most common comorbidities in

Correspondence: Adrian Sebastian Suhendro, Faculty of Medicine, Universitas Padjadjaran, Jalan Raya Bandung-Sumedang Km.21, Jatinangor, Sumedang, Indonesia, Phone: +6281321119225 Email: adriansebastiansuhendro@gmail.com 
COPD patients. ${ }^{7}$

The exact mechanism linking COPD and comorbidities is not yet known.11 A study by Barnes ${ }^{11}$ and Boschetto et al. ${ }^{12}$ suggested systemic inflammation as the linking mechanism. Patients with COPD have a peripheral lung inflammation which may 'spill over' to systemic circulation and cause an increase of acute-phase proteins (C-reactive protein and serum amyloid A (SAA)) and circulating cytokines (interleukin (IL)-1 $\beta$, IL6, IL-18, and tumor necrosis factor (TNF)- $\alpha$ ).

Smoking is the most important risk factor of COPD. ${ }^{7}$ According to WHO, Indonesia is ranked fourth in the total number of smokers in the world, third in total number of men smokers and seventeenth for women smokers. ${ }^{13}$ According to the national basic health research 2010 (riset kesehatan dasar/Riskesdas 2010), the percentage of population aged $>15$ years who smoke every day was $28.2 \%{ }^{14}$ West Java ranked twelfth for the prevalence of smokers in Indonesia. ${ }^{14}$ Dr. Hasan Sadikin General Hospital is the provincial referral hospital of West Java and it manages a large amount of
COPD patients. However, the comorbidities of COPD patients in this hospital have not yet to be known. This study aimed to determine the frequency, type and number of comorbidities accompanied in COPD patients.

\section{Methods}

The study was a retrospective, cross-sectional study carried out in the respirology and critical care outpatient clinic of Dr. Hasan Sadikin General Hospital, Bandung, Indonesia. The total sampling method was done to COPD patients' medical records at respirology and critical care outpatient clinic of Dr. Hasan Sadikin General Hospital in January-December 2012. Patients with obstructive pulmonary function test results in the medical record were included in this study while patients with no pulmonary function test result or test result stated the pulmonary function as 'restrictive' or 'normal' were excluded. This study was approved by Health Research Ethics Committee of the Faculty of Medicine,

Table 1 Respondents Characteristic

\begin{tabular}{|c|c|c|c|}
\hline Variable & $\begin{array}{c}\text { COPD with } \\
\text { Comorbidities } \\
(n=26)\end{array}$ & $\begin{array}{c}\text { COPD without } \\
\text { Comorbidities } \\
(n=12)\end{array}$ & $\begin{array}{c}\text { Total } \\
(n=38)\end{array}$ \\
\hline \multicolumn{4}{|l|}{ Sex } \\
\hline Male & 22 & 9 & 31 \\
\hline Female & 4 & 3 & 7 \\
\hline Age (median(range)) & $64(43-82)$ & $59(43-82)$ & $67(43-77)$ \\
\hline \multicolumn{4}{|l|}{ Age (years old) } \\
\hline$\leq 60$ & 13 & 2 & 15 \\
\hline $61-70$ & 4 & 6 & 10 \\
\hline $71-80$ & 6 & 4 & 10 \\
\hline$\geq 81$ & 3 & 0 & 3 \\
\hline \multicolumn{4}{|l|}{ Smoking History } \\
\hline Smokers & 8 & 4 & 12 \\
\hline Non Smokers & 0 & 0 & 0 \\
\hline Unknown & 18 & 8 & 26 \\
\hline \multicolumn{4}{|l|}{ Severity of Disease } \\
\hline GOLD 1 & 1 & 1 & 2 \\
\hline GOLD 2 & 10 & 4 & 14 \\
\hline GOLD 3 & 11 & 4 & 15 \\
\hline GOLD 4 & 4 & 3 & 7 \\
\hline
\end{tabular}


Table 2 Number of Comorbidities Suffered by One Subject

\begin{tabular}{lcc}
\hline & Comorbidity & n \\
\hline COPD only (or 'none') & 12 \\
COPD + 1 or more & 26 \\
COPD + 2 or more & 18 \\
COPD + 3 or more & 10 \\
COPD +4 & 2 \\
\hline
\end{tabular}

Universitas Padjadjaran and Dr. Hasan Sadikin General Hospital, Bandung, Indonesia.

Data were analyzed using Microsoft Office Excel 2010. Data were classified by age, gender, smoking history and severity of disease. Severity of disease was determined by using Global Initiative for Chronic Obstructive Lung Disease (GOLD) classification. ${ }^{7}$ Comorbidity was defined as other medical conditions occurred in subjects except pulmonary hypertension as a complication of COPD. We described the frequency of comorbidities in COPD cases, as well as the type and number of comorbidities accompanying COPD in each subject.

\section{Results}

Thirty eight COPD patients with obstructive pulmonary function test results were analyzed (Table 1). They consist of 31 males and 7 females, with age ranged between $43-82$ years and median age of 64 years. Severe obstruction is the most common pulmonary function test results found in subjects (15 subjects). Twelve patients have a history of cigarette smoking while smoking history is unknown in 26 remaining subjects. Of all COPD patients, 26 had at least one comorbidity (Table 2) while two of them have four comorbidities.

Comorbidities that frequently occurred among COPD patients were hypertension (9 of 38), coronary artery disease (5 of 38), heart failure ( 5 of 38), anemia ( 4 of 38) and benign prostate hyperplasia (3 of 38) (Table 3).

\section{Discussion}

This study found 26 of 38 COPD patients at a referral hospital having comorbidities, lower than the ones that found in family practice obtained from cross-sectional study using data from National Health and Nutrition Examination Survey of USA in 1999-2008
(96.4\%) or a study by Fumagalli et al. ${ }^{15}$ (94.1\%) ${ }^{8,9}$ Apart from the differences in study location and potential risk factors, our small simple size may explain this difference.

This study found more male COPD patients (31 of 38 subjects). This is similar to the national survey which found COPD prevalence in male $(5.3 \%)$ to be greater than female $(1.4 \%) .{ }^{8}$ Same results are shown in the studies by Almagro et al. ${ }^{16}$ (353 of 398 subjects) and Yamasaki et al. ${ }^{4}$ (462 of 608 subjects). One explanation may be that cigarette smoking as a risk factor of COPD is more common in male than female. According to WHO, 67.4\% men and $4.5 \%$ women in Indonesia are active smokers. ${ }^{13}$

Most COPD patients found in our study aged 60 or younger. It is younger than that found by Almagro et al. ${ }^{16}$ where the COPD patients aged between 70-80 years old. It might be due to the fact that we recruited patients' medical records at an outpatient while the other study at an inpatient clinic.

Despite the age difference, the severity of pulmonary obstruction found in our study is similar to that of the study by Almagro et al. ${ }^{16}$ at GOLD 3. While a study by Yamasaki et al. $^{4}$ at the Tottori University Hospital, Japan, had COPD patients with GOLD 1 as the most frequent patients' severity. Obstruction in COPD patient can be caused by 'small airway disease' such as airway inflammation, airway fibrosis, luminal plugs, or increased airway resistance, and parenchymal destruction, such as loss of alveolar attachments or decrease of elastic recoil. ${ }^{7}$ COPD exacerbation can also affect the severity of illness by decelerating the rate of lung function. ${ }^{7}$

The type of comorbidities that frequently occurred in this study was hypertension, as corroborated by other studies except a study by Ekstrom et al. ${ }^{17}$ in Sweden where heart failure is the most common comorbidity. $8,9,15,16$ contractively, the Swedish National Oxygen Register, as explained in their paper, found ahigh 
Table 3 Type of Comorbidities

\begin{tabular}{|c|c|c|c|}
\hline Comorbidities & $\begin{array}{c}\text { Male } \\
(n=31)\end{array}$ & $\begin{array}{c}\text { Female } \\
(n=7)\end{array}$ & Total \\
\hline Hypertension & 8 & 1 & 9 \\
\hline Coronary Artery Disease & 5 & 0 & 5 \\
\hline Heart Failure & 5 & 0 & 5 \\
\hline Anemia & 3 & 1 & 4 \\
\hline Benign Prostate Hyperplasia & 3 & 0 & 3 \\
\hline Diabetes Mellitus & 2 & 0 & 2 \\
\hline $\begin{array}{l}\text { Diabetes Mellitus with Diabetic } \\
\text { Neuropathy }\end{array}$ & 2 & 0 & 2 \\
\hline Hypertensive Heart Disease & 2 & 0 & 2 \\
\hline Inguinal Hernia & 2 & 0 & 2 \\
\hline Pulmonary Tuberculosis & 2 & 0 & 2 \\
\hline Asthma & 0 & 1 & 1 \\
\hline Breast Cancer & 0 & 1 & 1 \\
\hline Bronchiectasis & 1 & 0 & 1 \\
\hline Cirrhosis & 1 & 0 & 1 \\
\hline Community Acquired Pneumonia & 0 & 1 & 1 \\
\hline Dilated Cardiomyopathy & 0 & 1 & 1 \\
\hline Diverticulitis & 1 & 0 & 1 \\
\hline Dyspepsia & 1 & 0 & 1 \\
\hline Epulis Fibromatosa & 1 & 0 & 1 \\
\hline Grave's Disease with Thyrotoxicosis & 1 & 0 & 1 \\
\hline Hospital-Community Acquired Pneumonia & 1 & 0 & 1 \\
\hline Hemorrhoid & 1 & 0 & 1 \\
\hline Liver Cancer & 1 & 0 & 1 \\
\hline Peptic Ulcer & 0 & 1 & 1 \\
\hline Rectal Cancer & 0 & 1 & 1 \\
\hline Stroke Sequelle & 1 & 0 & 1 \\
\hline Thyroid Heart Disease & 1 & 0 & 1 \\
\hline Vesiculolithiasis & 1 & 0 & 1 \\
\hline
\end{tabular}

sensitivity and specificity for cardiovascular disease but low sensitivity for less serious and less acute condition such as hypertension. ${ }^{17}$ The exact mechanism linking hypertension and COPD has not yet known. Hypertension in COPD is probably due to smoking and old age as the sharing risk factor. ${ }^{8,12,15}$ Also, hypertension could happen because of increased arterial stiffness. ${ }^{15}$ Another study said that arterial stiffness occur frequently in COPD patients due to systemic inflammation. ${ }^{10}$ Furthermore, hypertension could happened because of insulin resistance which related with chronic systemic inflammation. ${ }^{18}$

Almagro et al. ${ }^{16}$ in his study once said that there was a different distribution of comorbidities in male and female COPD patients. In this study, hypertension is commonly found in male subjects. It is contrary to Garcia-Olmos et al. ${ }^{8}$, Almagro et al. ${ }^{16}$, and Ekstrom et al. ${ }^{17}$ study which said that hypertension as the comorbidity of COPD is 
commonly occurred in female. This might be related to tobacco smoking, as the sharing risk factor of COPD and hypertension, which more frequent in male than female in Indonesia. ${ }^{13}$ This difference of study result might happen due to different location of study which influences different culture and smoking behavior, particularly in female. According to WHO, prevalence of female smoker in developed country (22\%) are more than prevalence of female smoker in developing country (9\%).

Few cases of diabetes mellitus were found in this study (5.26\%). In addition, we could not found skeletal muscle dysfunction, osteoporosis, depression, and lung cancer as comorbidities in COPD patients. It is contrary to GOLD publication and Boschetto et al.12 study which said that besides cardiovascular disease, skeletal muscle dysfunction, metabolic syndrome osteoporosis, depression, and lung cancer are the most common comorbidities found in COPD patients. ${ }^{7}$ This might be happened because COPD patients that came to respirology and critical care outpatient clinic of Dr. Hasan Sadikin General Hospital did not get bone mass density (BMD) test as osteoporosis marker and mental health detection to screen depression. Patients with lung cancer may found in inpatient instead of outpatient facilities.

This study constraint is time and resources, the lack of information found in medical records, which resulted in several missing characteristics data. Furthermore, the onset of comorbidity in COPD patients is unknown

In conclusions, our study revealed high frequency of comorbidities in COPD patients and gives information that hypertension, coronary artery disease, and heart failure were the most frequent comorbidities which are found in COPD patients admitted to respirology and critical care outpatient clinic of Dr. Hasan Sadikin General Hospital in 2012.

In addition, due to the comorbidity which often occurs on the COPD patients, it is suggested that physician examine the comorbidity, primarily the most often occurred one, such as hypertension, coronary artery disease, and heart failure, to enhance the quality of health services.

\section{References}

1. Soeroto AY. Penyakit paru obstruktif kronis. In: Dahlan Z, Amin Z, Soeroto AY, editors. Kompendium tatalaksana penyakit respirasi \& kritis paru: Perhimpunan Respirologi Indonesia; 2012. p. 31-42.

2. Menzin J, Boulanger L, Marton J, Guadagno L, Dastani H, Dirani R, et al. The economic burden of chronic obstructive pulmonary disease (COPD) in a U.S. Medicare population. Respir Med. 2008;102(9):1248-56.

3. Senior R, Atkinson J. Chronic obstructive pulmonary disease: epidemiology, pathophysiology, and pathogenesis. In: Fishman A, Elias J, Fishman J, Grippi M, Senior R, Pack A, editors. Fishman's pulmonary diseases and disorders. 4th ed. New York: McGraw-Hill Education; 2008. p. 707-27.

4. Yamasaki A, Hashimoto K, Hasegawa Y, Okazaki R, Yamamura M, Harada T. COPD is frequent in conditions of comorbidity in patients treated with various diseases in a university hospital. Int J Chron Obstruct Pulmon Dis. 2010;5:351-5.

5. Salvi SS, Manap R, Beasley R. Understanding the true burden of COPD: the epidemiological challenges. Prim Care Respir J. 2012;21(3):249-51.

6. Tan WC, Ng TP. COPD in Asia: where East meets West. Chest. 2008;133(2):517-27.

7. Global strategy for the diagnosis, management, and prevention of chronic obstructive pulmonary disease, global initiative for chronic obstructive lung disease (GOLD). 2013 [cited 2013 September 25]. Available from: http:// www.goldcopd.org/.

8. Garcia-Olmos L, Alberquilla A, Ayala V, Garcia-Sagredo P, Morales L, Carmona M, et al. Comorbidity in patients with chronic obstructive pulmonary disease in family practice: a cross sectional study. BMC Fam Pract. 2013;14:11.

9. Schnell K, Weiss CO, Lee T, Krishnan JA, Leff $B$, Wolff JL, et al. The prevalence of clinically-relevant comorbid conditions in patients with physician-diagnosed COPD: a cross-sectional study using data from NHANES 1999-2008. BMC Pulm Med. 2012;12:26.

10. Wouters EFM, Celis MPM, Breyer MK, Rutten EPA, Graat-Verboom L, Spruit MA. Co-morbid manifestation in COPD. Respir Med: COPD Update. 2007;3(4):135-51.

11. Barnes PJ. Chronic obstructive pulmonary disease: effects beyond the lungs. PLoS medicine. 2010;7(3):e1000220.

12. Boschetto P, Beghe B, Fabbri LM, Ceconi C. Link between chronic obstructive pulmonary disease and coronary artery 
disease: implication for clinical practice. Respirology. 2012;17(3):422-31.

13. WHO. Global adult tobacco survey: Indonesian report 2011[cited 2014 January 7]. Available from: www.searo. who.int/entity/tobacco/data/gats_ indonesia_2011.pdf.

14. Badan Penelitian dan Pengembangan Kesehatan Kementerian Kesehatan RI. Riset kesehatan dasar (Riskesdas 2010). 2010 [cited 2013 November 14]. Available from: http://www.litbang.depkes.go.id/ sites/download/buku_laporan/lapnas_ riskesdas2010/Laporan_riskesdas_2010. pdf.

15. Fumagalli G, Fabiani F, Forte $S$, Napolitano $\mathrm{M}$, Marinelli P, Palange $\mathrm{P}$, et al. INDACO project: a pilot study on incidence of comorbidities in COPD patients referred to pneumology units. Multidiscip Respir Med. 2013;8(1):28.

16. Almagro P, Lopez Garcia F, Cabrera F, Montero L, Morchon D, Diez J, et al. Comorbidity and gender-related differences in patients hospitalized for COPD. The ECCO study. Respir Med. 2010;104(2):253-9.

17. Ekstrom MP, Jogreus C, Strom KE. Comorbidity and sex-related differences in mortality in oxygen-dependent chronic obstructive pulmonary disease. PLoS One. 2012;7(4):e35806.

18. Fabbri LM, Luppi F, Beghe B, Rabe KF. Complex chronic comorbidities of COPD. Eur Respir J. 2008;31(1):204-12. 